\title{
CHINESE TOURISTS IN CRACOW, POLAND: THEIR PROFILE, EXPECTATIONS, AND PERCEPTIONS
}

\author{
PAULINA GUSZKIEWICZ, KAROLINA NESSEL \\ Jagiellonian University in Kraków, Faculty of Management and Social Communication, \\ Chair of Management in Tourism
}

\author{
Mailing address: Karolina Nessel, Jagiellonian University in Kraków, Chair of Management in Tourism, \\ 4 Łojasiewicza Street, 30-348 Kraków, tel.: +48 12 6645704, fax: +48 12 4223229, e-mail: karolina.nessel@uj.edu.pl
}

\begin{abstract}
Introduction. In 2012, China became the largest spender in international tourism, benefiting many destinations worldwide. Even if for Poland it is not an important source market yet, the Polish authorities have undertaken some marketing activities in China. The main aim of the paper is to explore the profile, motivations, and perceptions of the Chinese tourists visiting Cracow. The secondary aim is to check the effectiveness of the marketing efforts dedicated to the Chinese market undertaken by Poland since 2010. Material and methods. Data for the study $(\mathrm{n}=100)$ were collected using a paper survey in English carried out among mainland Chinese tourists in Cracow in 2015. Results. The Chinese usually visit Poland for the first time, often in transit. They are prompted by the information found online and by word of mouth. Their main reasons to come are tradition, culture, historical sites, landscapes, and low costs. These expectations are well fulfilled, and the tourists' overall satisfaction is very high. The Chinese find Poland to be different from other Western European countries. For them, Poland is a remarkable, traditional, safe, and developing country. Yet, their knowledge about the destination is limited. The main problem encountered is the language barrier, both online and once on site. The marketing efforts undertaken by Poland in the Chinese market have had weak and ambivalent effects. Conclusions. In order to attract Chinese tourists, there is a need to intensify expenditure not only on promotion (mainly online) but also on the removal of language-based communication problems. There is also scope for expanding the tourist offer dedicated to Chinese tourists - both in Poland and in cooperation with other Central European countries.
\end{abstract}

Key words: Chinese outbound tourists, Cracow, destination image, tourist behaviour, tourist motivation

\section{Introduction}

Over the last 6 decades, tourism has grown into one of the largest and most dynamic sectors of the world economy. It has also become one of the most internationalised industries. For many years, despite some occasional shocks (like the financial crisis of 2008-2009), international tourism has demonstrated a clear positive dynamics, with international tourist arrivals hitting a record of 1,133 million worldwide in 2014 (an average annual rise of $4 \%$ from 2004 to 2014) and total international receipts reaching 1,197 billion USD in 2014 (an average annual rise of $10 \%$ from 2004 to 2014) [1, 2].

An important part of this phenomenon is the rise of emerging economies as source markets. A growing middle class, travel facilitation, and an easing of restrictions on foreign travel have made many emerging economies rapidly increase their share of world tourism over the past decade [1]. Worth mentioning in this context are especially the Russian Federation (already the $5^{\text {th }}$ top spender in the ranking of international tourism expenditure in 2014, compared to the $9^{\text {th }}$ place in 2004) and Brazil (moving to the $10^{\text {th }}$ place in 2014 , compared to the $29^{\text {th }}$ place in 2005).

Yet, the most striking development can be observed in the case of China - after two decades of very vigorous growth, it has become the largest spender in international tourism worldwide already in 2012 (ranking only $7^{\text {th }}$ in 2005), surpassing such long established top source markets as the United States and Germany (tab. 1).
China generates already over 13\% of global tourism receipts, and given its economic perspectives, this share is deemed to grow in the near future. Chinese outbound tourism benefits many destinations worldwide, particularly in Asia and the Pacific. Also Europe has been experiencing a considerable rise in the numbers of Chinese travellers and their expenditure (tab. 2). The European countries benefiting most from this growing source market are mainly Italy, Germany, Switzerland, Great Britain, and France $[8,9]$.

Naturally, the current and potential extra inflow of tourist revenue from China has been noticed by the industry and has led to many active adaptations to the specificities of this new client. Simultaneously, companies and destinations have engaged in competitive marketing efforts in this dynamic source market.

At present, Poland is not on the top destinations list of Chinese travellers. Neither is China an important source market for Poland yet; Chinese travellers accounted for only $1.1 \%$ of the foreign tourists staying in hotel accommodation in 2015 (60,525 persons) - a clear rise from $0.6 \%$ (25,579 persons) in 2010 [12]. Nevertheless, recognising the potential of this market, the Polish Tourist Organisation classified China as the second most important source market in the strategic document "Marketing Strategy of Poland in Tourism for 2012-2020" already in 2008. Consequently, some communication activities have been undertaken, of which the most important ones have been: participation in the World Expo in Shanghai in 2010, the promotion of the Chopin Year Celebration in 2010, and the promotional campaign "Poland. Come and find your story" in 2013. 
Table 1. Top spenders in international tourism, 2009-2014, countries ranked by total expenditure in 2014

\begin{tabular}{|c|c|c|c|c|c|c|c|c|c|c|c|c|c|c|c|c|c|c|}
\hline & \multicolumn{4}{|c|}{$\begin{array}{c}\text { International expenditure } \\
\text { (USD billion) }\end{array}$} & \multicolumn{4}{c|}{ Share in world market (\%) } & \multicolumn{4}{c|}{ Annual local currency change* (\%) } \\
\hline & 09 & 10 & 11 & 12 & 13 & 14 & 09 & 10 & 11 & 12 & 13 & 14 & 09 & 10 & 11 & 12 & 13 & 14 \\
\hline 1. China & 43.7 & 54.9 & 72.6 & 102 & 128.6 & 164.9 & 5.1 & 5.9 & 7.0 & 9.5 & 11.1 & 13.2 & $20.9^{*}$ & $25.6^{*}$ & $32.2^{*}$ & 37.2 & 23.8 & 27.1 \\
\hline 2. USA & 74.1 & 75.5 & 79.1 & 83.5 & 104.1 & 110.8 & 8.7 & 8.1 & 7.7 & 7.8 & 7.4 & 8.9 & -7.9 & 1.9 & 4.8 & 6.7 & 3.8 & 6.4 \\
\hline 3. Germany & 81.2 & 78.1 & 84.3 & 83.8 & 91.4 & 92.6 & 9.5 & 8.4 & 8.2 & 7.8 & 7.4 & 7.4 & -5.9 & 1.3 & 2.8 & 5.8 & 5.7 & 0.9 \\
\hline 4. UK & 50.1 & 50 & 50.6 & 52.3 & 52.7 & 57.6 & 5.9 & 5.4 & 4.9 & 4.9 & 4.5 & 4.6 & -13.6 & 0.5 & -2.4 & 4.1 & 3.5 & 3.8 \\
\hline 5. Russia & 20.9 & 26.6 & 32.5 & 42.8 & 53.5 & 50.4 & 2.5 & 2.9 & 3.2 & 4.0 & 4.6 & 4.0 & $-12.1^{*}$ & $27.2^{*}$ & $22.1^{*}$ & 36.5 & 28.9 & 13.7 \\
\hline 6. France & 38.5 & 38.5 & 41.7 & 37.2 & 42.9 & 47.8 & 4.5 & 4.2 & 4.0 & 3.5 & 3.7 & 3.8 & -1.9 & 5.7 & 3.0 & -8.7 & 3.9 & 11.3 \\
\hline 7. Canada & 24.2 & 29.6 & 33 & 35.1 & 35.2 & 33.8 & 2.8 & 3.2 & 3.2 & 3.3 & 3.0 & 2.7 & -4.8 & 10.0 & 7.2 & 6.2 & 3.2 & 3.3 \\
\hline
\end{tabular}

* USD; own elaboration on UNWTO data [1, 3, 4, 5, 6, 7].

Table 2. Chinese outbound tourism, 2010-2017

\begin{tabular}{|c|c|c|c|c|c|c|c|c|}
\hline & 2010 & 2011 & 2012* & $2013^{*}$ & $2014^{*}$ & $2015^{*}$ & $2016^{*}$ & $2017^{*}$ \\
\hline Expenditure (USD millions) & 59.84 & 78.94 & 90.16 & 109.79 & 133.85 & 160.21 & 192.21 & 227.95 \\
\hline Annual change in expenditure (\%) & & 31.9 & 14.2 & 21.8 & 21.9 & 19.7 & 20.0 & 18.6 \\
\hline International departures (thousands) & 55456 & 64770 & 67753 & 75853 & 85033 & 93515 & 102969 & 112189 \\
\hline Annual change in international departures (\%) & & 16.8 & 4.6 & 11.9 & 12.1 & 9.9 & 10.1 & 8.9 \\
\hline Expenditure per international departure (USD) & 1079 & 1218 & 1330 & 1447 & 1574 & 1713 & 1866 & 2031 \\
\hline $\begin{array}{l}\text { Annual change in expenditure per international } \\
\text { departure }(\%)\end{array}$ & & 12.8 & 9.1 & 8.7 & 8.7 & 8.83 & 8.93 & 8.8 \\
\hline Arrivals to Europe (thousands) & 2160 & 2263 & 2370 & 2528 & 2689 & 2818 & 2959 & 3093 \\
\hline Annual change in arrivals to Europe (\%) & & 4.7 & 6.7 & 6.3 & 4.7 & 4.8 & 5.0 & 4.5 \\
\hline $\begin{array}{l}\text { Share of departures to Europe in total } \\
\text { Chinese international departures (\%) }\end{array}$ & 3.9 & 3.5 & 3.5 & 3.3 & 3.2 & 3.0 & 2.8 & 2.8 \\
\hline
\end{tabular}

* forecast; [10] in [11].

All these undertakings were to create or enhance Poland's image as a country worth visiting. In research on tourist marketing, the destination image is generally agreed to be the critical factor of destination choice and its subsequent evaluation [13, $14,15]$. Being a mental construct, this image encompasses both factual knowledge about the destination and individual, subjective perceptions about it [16].

As of 2016, there have been no large-scale studies of the perception Chinese tourists arriving to Poland have about the country as a destination and about the promotional efforts Poland has undertaken. Therefore, the main aim of the paper is to explore the profile, motivations, and perceptions of the Chinese tourists visiting Cracow, Poland (Cracow is one of the top tourist destinations in Poland and has been indicated, besides Warsaw, as the most popular Polish destination among Chinese tourists in the "Marketing Strategy" [17]). The secondary aim is to check the effectiveness of the marketing efforts dedicated to the Chinese market undertaken by Poland since 2010 .

\section{Material and methods}

Data for the study were collected using a survey. The anonymised and standardised paper questionnaires in English were distributed to mainland Chinese tourists near the 4 SeeKrakow Info Points in Cracow: at the Main Train Station, the Wyspiański Pavilion (Wszystkich Świętych 2 Street), Floriańska 6 Street, and in the underground passage connecting the Main Train Station and the Old Town (all of them are situated in the tourist centre of the city). Thus, the sample included tourists at different stages of their travel. The subjects were selected and interviewed by one of the authors. This way some additional comments were retrieved, and the precision of all the answers was assured. The data collection lasted from April to mid-August 2015. In the end, 100 questionnaires were retained for investigation.

Given that there were 2.52 million foreign tourist arrivals to Cracow in 2015 and that tourists from China constituted 0.36\% of that group (i.e. approximately 9,000 persons) [18], the sample of 100 generated estimates of the entire population with a general margin error of $10 \%$ and confidence level of $95 \%$.

Of the sample, just over half (54\%) were women, with a clear predominance of young people, who were mostly students (tab. 3). Half of them were travelling with friends or relatives, and one-fourth were visiting with a partner. The questioner managed to conduct only 10 surveys with persons travelling in an organised group, due to the lack of a common language. Therefore, this kind of traveller was underrepresented in the sample. Moreover, as convenience sampling was applied and limited only to tourists visiting the information points, some other tourist profiles may be underrepresented (e.g. tourists hiring guides). Hence, no breakdown of the sample by tourist profile was carried out in the analysis. 
Table 3. General characteristics of the sample (percentage of respondents)

\begin{tabular}{|c|c|c|c|c|c|c|}
\hline SEX/AGE & Total & $\mathbf{1 8 - 2 9}$ & $\mathbf{3 0 - 3 9}$ & $\mathbf{4 0 - 4 9}$ & $\mathbf{5 0 - 5 9}$ & $\mathbf{6 0 +}$ \\
\hline All & 100 & 74 & 10 & 2 & 7 & 7 \\
\hline Women & 54 & 36 & 10 & 2 & 4 & 2 \\
\hline Men & 46 & 38 & 0 & 0 & 3 & 5 \\
\hline
\end{tabular}

\begin{tabular}{|c|c|c|c|c|c|}
\hline \multirow{2}{*}{ OCCUPATION } & Student & Employee & Pensioner & $\begin{array}{c}\text { Business } \\
\text { owner }\end{array}$ & Other \\
\cline { 2 - 6 } & 70 & 15 & 5 & 2 & 8 \\
\hline
\end{tabular}

\begin{tabular}{|c|c|c|c|c|}
\hline $\begin{array}{c}\text { WHO ARE YOU } \\
\text { TRAVELLING WITH? }\end{array}$ & $\begin{array}{c}\text { With friends } \\
\text { or family }\end{array}$ & $\begin{array}{c}\text { With } \\
\text { partner }\end{array}$ & Alone & $\begin{array}{c}\text { In an organised } \\
\text { group }\end{array}$ \\
\cline { 2 - 5 } & 50 & 25 & 16 & 10 \\
\hline
\end{tabular}

The analysis of the sample consisted of two stages. First, the material was presented in a quantitative form. Then, descriptive statistics were calculated and displayed in a graphic form.

\section{Results}

The first set of questions aimed to determine the general tourist profile of the responders. Figure 1 illustrates the respondents' choices and ratings of the most important factors considered when choosing a travel destination. Clearly, the most important variable was the presence of tourist attractions (the highest number of indications and the second top mean with a very low standard deviation). Second came costs, cuisine, ambiance, and security. On the other hand, weather conditions turned out to be the least important.

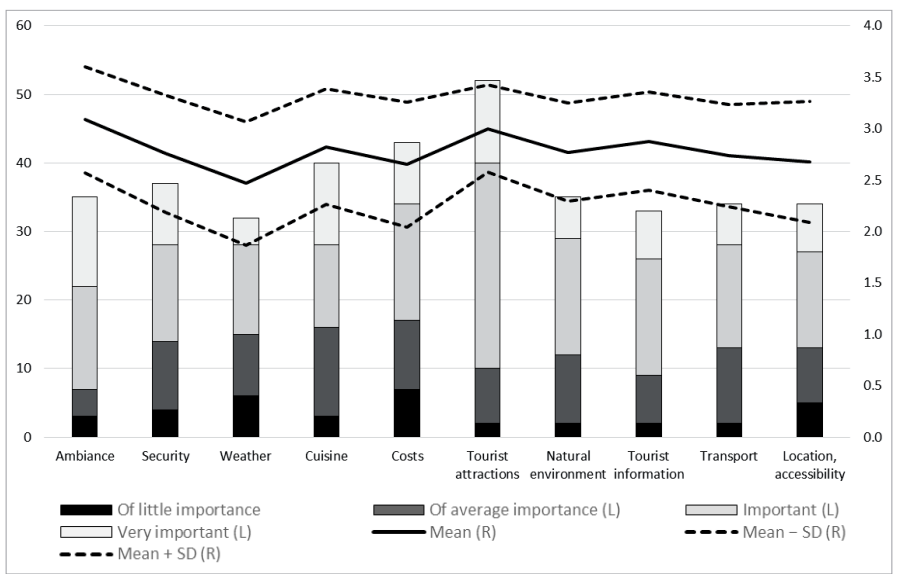

Ratings: of little importance $=1$, of average importance $=2$, important $=3$, very important $=4$. Respondents were asked to choose and rate 5 factors among 10.

Figure 1. Factors influencing the choice of a tourist destination (cumulative number of indications (left axis) and mean \pm standard deviation (right axis))

In the next question, respondents identified the places they were interested in while travelling. Evidently, the most interesting places were castles (for $66 \%$ of respondents), followed by museums (46\%), churches (42\%), and parks (36\%). Less interest was evoked by SPAs (18\%), theatres (16\%), shopping malls (14\%), and operas (12\%). Additionally, 10 respondents mentioned other attractions (i.a. beaches, monuments, waterparks, and zoos).
Turning to the respondents' actual visit in Poland and Cracow, for most of them (78\%), it was their first visit in Poland, and for $68 \%$, Cracow was just one of the stages of their trip. In the region of Malopolska, besides Cracow, the tourists were going to visit mainly Auschwitz-Birkenau (50\% of them), with Zakopane and the Wieliczka Salt Mine indicated only by $18 \%$ and $16 \%$, respectively.

The main declared goal of their trip to Poland was clearly tourism ( $72 \%$ indications), followed by university studies (24\%). Only 4 persons came mainly for business, and no one specified shopping as a leading reason.

The question about the main motivation was supplemented by the request to indicate up to 5 among 10 suggested factors influencing the choice of Poland as a travel destination (fig. 2). The most often designated one was tradition and culture (39\%), followed by a rich history, tourist attractions, landscapes, and low costs (25-31 indications). Only 6 persons had chosen Poland because of its security, and only 2 had decided to visit because of its location. In the additional comments, respondents gave some other reasons for their visit in Poland, such as their interest in Jewish culture, desire to visit Auschwitz-Birkenau, desire to get to know the Polish culture and shared history, curiosity about Poland's communist past, and the fact that there are few Chinese people who have been to Poland.

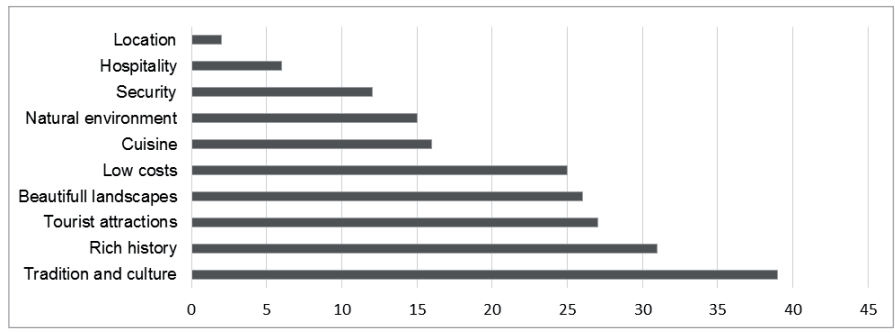

Figure 2. Factors influencing the choice of Poland as a tourist destination (number of indications)

The tourists declared that they had been encouraged to come to Poland mainly by information found online $(42 \%)$ and by the recommendations of their families and friends (40\%). Information in guidebooks and previous visits had motivated only $6 \%$ of them. Even fewer of them were driven by commercials in traditional media $(4 \%)$ or travel agency offers $(2 \%)$. Some respondents stressed the encouragement of the Chinese government to visit and study in Poland.

When asked about their sources of the information about Poland as a travel destination, 90\% of respondents indicated the Internet, with TripAdvisor being the main source, supplemented by other websites in English. The respondents often expressed criticism about the insufficiency of information in Chinese and on Chinese websites. This was seen as an important factor making independent travel to Poland difficult, or even impossible. Another important source of information used before arriving to Poland was guidebooks (for $26 \%$ of respondents). In contrast, the press was used only by $8 \%$ of respondents, and the website of the Polish Embassy in Beijing was visited by $6 \%$ of them. None of the respondents indicated TV commercials or billboards.

The next section of the survey related to the respondents' perception of Poland as a tourist destination once they had arrived. When asked to rate some general issues, the tourists assessed the natural environment, tourist information provided in the country, and accessibility from other European countries 
as good on average. Clearly less favourable opinions (but still positive on average) were expressed about the accessibility of promotional materials concerning Poland in China and about Polish hospitality and the attitude towards visitors (fig. 3 ). In the latter case, only $17 \%$ of respondents rated it as very good, $44 \%$ evaluated it as good, $30 \%$ had no opinion, and $9 \%$ found it poor.

This question was complemented by another one asking respondents to indicate their agreement/disagreement with some statements about Poland and Cracow (fig. 4). Once again the availability of information about Poland was evaluated poorly. This seems in line with a clearly negative opinion about Poland's promotion in China. Still, other ratings were quite positive: the majority of the respondents found Poland a popular destination (52\%) and thought that most other people had a positive opinion about Poland (58\%). Very positive answers were given concerning the respondents' evaluation of their stay in Poland: $90 \%$ of respondents agreed with the statement "I would recommend Poland as a tourist destination to my family and friends" (of which as many as 50\% agreed strongly with this statement, with not a single person disagreeing with it), and $80 \%$ found Poland worth the money spent (of which $36 \%$ agreed strongly, $44 \%$ agreed, $14 \%$ did not know, and only $6 \%$ rather disagreed). Finally, 42\% declared they were willing to visit Poland again (with only $5 \%$ disagreeing with this statement, while $53 \%$ did not know). Likewise, Cracow was evaluated well in relation to its unique tourist image and organisation of cultural events ( $86 \%$ and $83 \%$ of respondents agreed or strongly agreed with these statements).

The survey continued with a set of 3 questions testing the respondents' perception of Poland from different perspectives (fig. 5-7). In the question concerning the respondents' associations with Poland in general, there was no answer shared by the majority. The feature indicated most often was Poland's long and rich history (41 votes), contrary to its modernity (chosen only by $8 \%$ of respondents). Poland was seen as different from other Western countries, as a country that is safe, remarkable, and inspiring, rather than dynamic, active, ecological, or modern (fig. 5). This view was largely confirmed by answers to the following question about the reasons why it is worth visiting Poland (fig. 6). The most often chosen reasons were historical sites, tourist attractions, landscapes, interesting places, and low prices (more than 20 indications). Evidently, the Polish cuisine or geographical location were not a sufficient reason. Consistently, the location understood as the distance from China turned out to be the main reason discouraging people from coming to Poland (62 indications) (fig. 7). Only few people found the prices or the lack of cultural events or historical sites discouraging. However, 22 Chinese tourists found Poles' impoliteness demotivating (whereas only 16 tourists indicated "nice and open-minded people" in the preceding question as a reason to visit the country). Some tourists had their own ideas about what demotivates people to

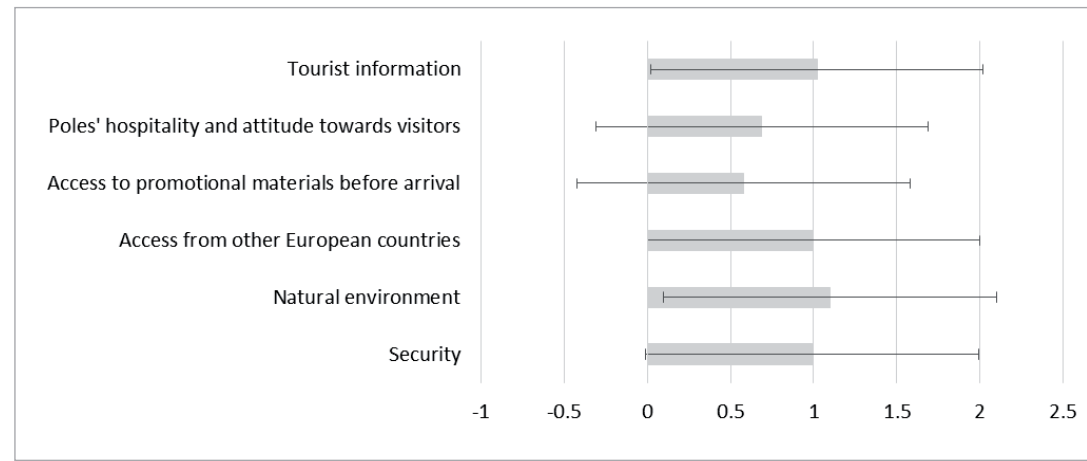

Ratings: very bad $=-2$, bad $=-1, I$ don't know $=0$, good $=1$, very good $=2$.

Figure 3. Respondents' ratings of some aspects of Poland as a tourist destination (mean \pm standard deviation)

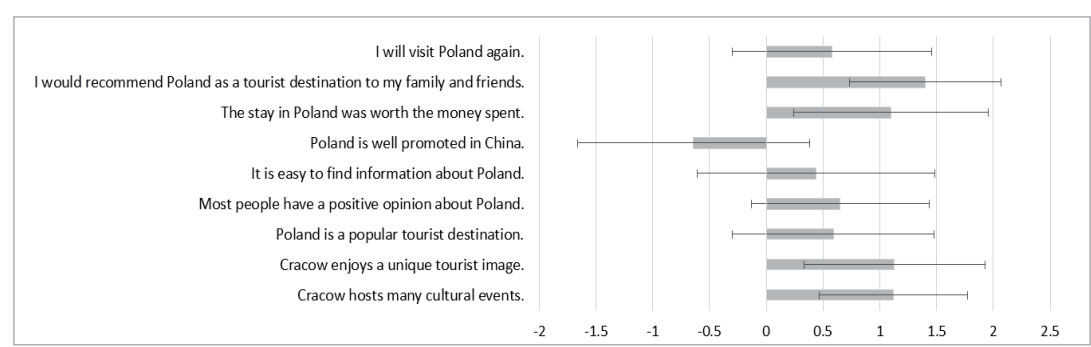

Ratings: strongly disagree $=-2$, disagree $=-1$, I don't know $=0$, agree $=1$, strongly agree $=2$.

Figure 4. Respondents' opinions of some aspects of Poland and Cracow as tourist destinations (mean \pm standard deviation)

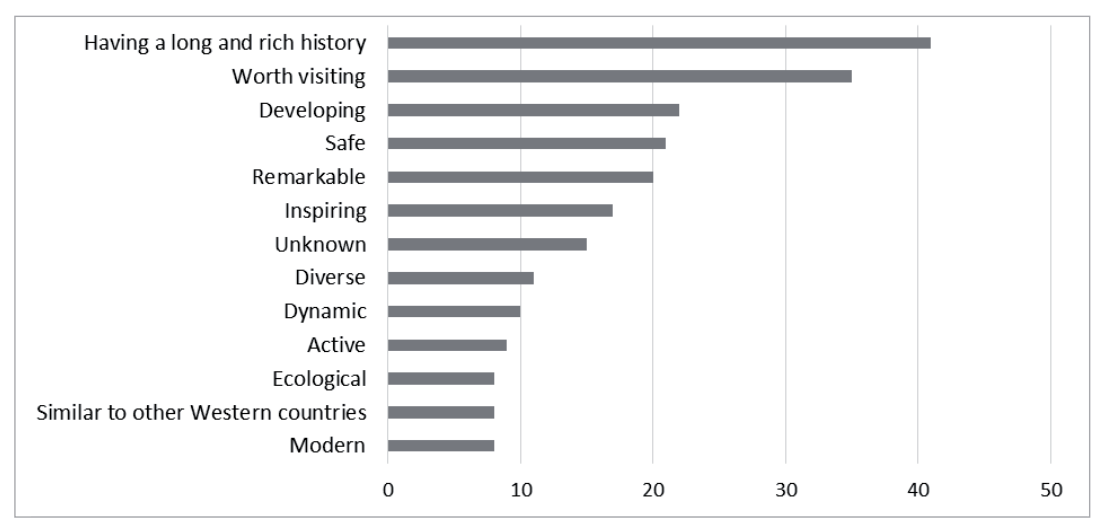

Figure 5. Respondents' associations with Poland (number of indications)

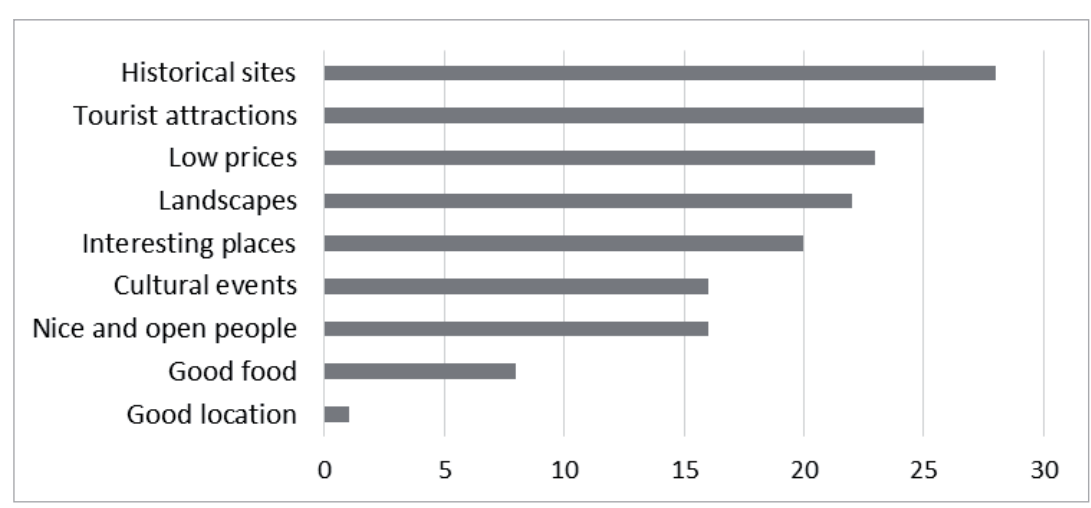

Figure 6. Respondents' answers to the question: Why is it worth visiting Poland? (number of indications) 


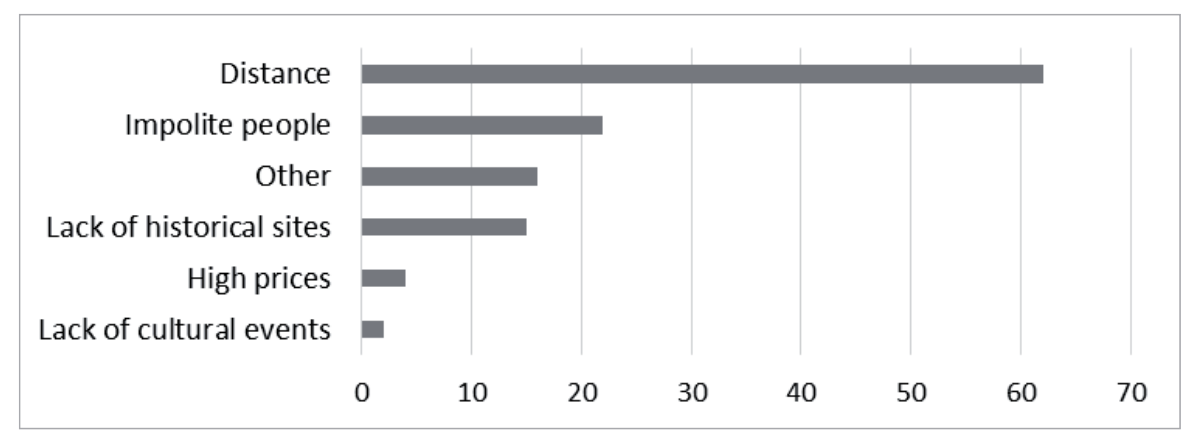

Figure 7. Respondents' answers to the question: What discourages people from visiting Poland? (number of indications)

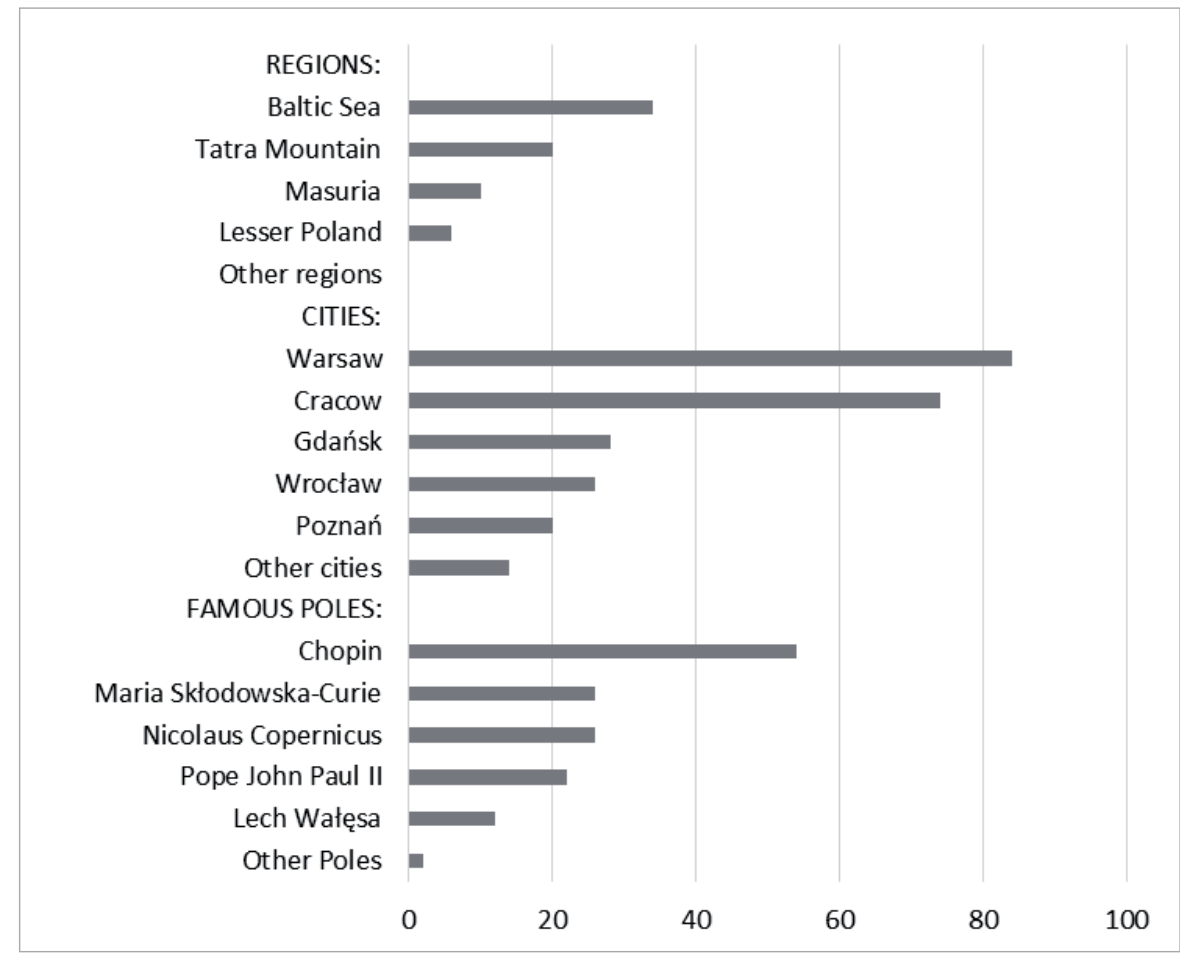

Figure 8. Respondents' knowledge about Poland (number of tourists indicating such knowledge)

visit Poland (these were mainly: a lack of information and promotion of Poland and problems with communication).

In order to better understand the reasons demotivating Chinese tourists to visit Poland, the respondents were also asked an open-ended question about things they had enjoyed in other destinations which were missing in Poland. The most frequent response was related to language barriers in communication (both in Chinese and English). The respondents thought it was difficult to find someone speaking English, not to mention a Chinese speaker, in Poland, whereas they had experienced fewer such problems in other countries, where they had often been served in Chinese. They also missed good Chinese food and Chinese guides. Less frequent answers related to the lack of ambiance (as in "romantic Paris"), theme parks, and Wi-Fi connection in trains.

At the end of this part of the survey, another open-ended question was formulated about the respondents' connotations with Poland. The most frequent answer was history (with some other indications such as Auschwitz, pain, nature, cold weather, and large portions of food), confirming in general the connotations identified in a multiple-choice question asked earlier in the survey.

The next part of the survey tested the respondents' knowledge about Polish regions and cities as well as the most famous Polish people (fig. 8). Only Warsaw, Cracow, and Chopin were declared to be known by most of the respondents. Very few (only 6\%) respondents visiting Cracow confirmed they knew the region of Malopolska (Lesser Poland).

The final part of the survey related to the promotion of Poland in China. In fact, only 18 respondents knew any promotional activities of this sort. The most often indicated ones were the campaign "Poland. Come and fine your story" and the exposition in Shanghai (both received 10 indications). Only 6 tourists had heard about the Chopin Year Celebration in 2010, and 3 tourists claimed to know some other actions. In the last question, the respondents were to evaluate whether the slogan "Poland. Come and find your story" appropriately reflects the nature of Poland. On a scale from 1 to 10 (where 1 stood for the 
lowest possible rating and 10 was the highest possible rating), the average grade was 5.4 with a standard deviation of 1.6.

\section{Discussion}

Competing in the global market for foreign tourists' decisions to visit requires first of all an understanding of their perceptions about the destination, their motivations, and the barriers which discourage them from travelling.

The study has shown that for the Chinese tourists coming to Cracow, the most important factors of destination choice are tourist attractions (such as castles, museums, and churches) and costs. These observations are in line with the motivations to come to Poland indicated by the tourists: they chose Poland because of its tradition, culture and history, tourist attractions, and low costs. During their visit, they mostly got what they had expected. The reality reinforced their image of Poland as a country with a long and rich history, which is a rather traditional and developing country that is different than other Western countries, and with relatively low prices. The fact that their expectations had been fulfilled led to a generally high level of satisfaction, as measured by the readiness to recommend Poland as a travel destination, as well as by the largely shared opinion that the visit to Poland was worth the money spent. Also Cracow itself scored high in terms of its tourist and cultural image. The fact that Poland scored relatively low on the intention to be visited again may be attributed to the distance and nature of Chinese trips to Europe - for Chinese tourists, Europe is an expensive and far away destination, and when they get here, they are usually looking to visit as many countries as possible at once, for the sake of "doing them" (they may visit as many as 10 countries in a tour lasting 10 days [17, 19]).

Despite these generally positive opinions, the study has also determined some less favourable perceptions of Poland in the eyes of Chinese tourists. Particularly important is the issue of the communication barriers the tourists encounter - having travelled to other destinations which are more popular with the Chinese and more adapted to their needs, they found the problems to communicate in Chinese or even in English and the lack of informational materials in Chinese quite stressful and impeding individual travel. Somewhat surprising is the relatively low (even if still positive) opinion the Chinese tourists got about Polish hospitality and friendliness (usually evaluated quite high by other tourists [18]). This may be due to the communication issues. Less surprising is their low enthusiasm for the Polish cuisine - the Chinese are known to have little curiosity for local food and to prefer eating Chinese food while on a foreign trip [20].

Even if generally the perceptions Chinese tourists have about Poland are good or even very good, their knowledge of the destination is rather poor. The only cities known by the majority of them are Warsaw and Cracow. Even when visiting Cracow, most of them declared they did not know the region of Malopolska and were not going to visit it. Clearly there are two reasons for this situation. The first one is the way many Chinese tourists travel in Poland - it is not their main destination, and they spend only a few days here in transit from/to Prague or Budapest. For most of them, this short trip is the first and probably the last visit in Poland (as they are not going to return because of the distance and lack of time). Combined with the communication problems they encounter, the visit in Poland does not really seem to broaden their knowledge about the country.

The other reason for their weak knowledge of Poland is the quasi-inexistent promotion of Poland in China and lack of on- line information about Poland in the Chinese language and on Chinese websites and social media. The activities undertaken by the Polish authorities had been noticed only by a very small portion of the respondents. This is understandable, as the campaigns were limited by a relatively low budget (compared to the marketing efforts of other destinations in China). The results of this study also show that the decision to devote part of this financing to generating some content in the Chinese social media was correct (given that this was the main source of tourist information indicated by the respondents). On the other hand, the choice of promotional message could have been better.

These findings suggest that Poland's marketing efforts should concentrate more on informational materials in Chinese both on the Internet (websites, social media, or tourist mobile applications) and in the destination itself (tourist brochures and signage). There is also a clear need for Chinese-speaking guides.

Moreover, given Chinese tourists' propensity to visit many places in a relatively short time and the results of the study, it might be worth encouraging cooperation between Polish, Hungarian, and Czech tour operators to create a common package making it possible to visit the most beautiful places in Central Europe (the countries abound in castles, historic monuments, and natural landscapes, all of which were appreciated by the respondents). One should also try to promote longer visits in Poland offering tours of such attractions as the Trail of the Eagles' Nests or trips encompassing Cracow, the Wieliczka Salt Mine, Warsaw, Malbork Castle, the Baltic seaside, or Białowieża Forest.

\section{Conclusions}

Considering the main goal of the study, which was to explore the profile, motivations, and perceptions of the Chinese tourists visiting Cracow, the principal findings may be summarised as follows:

1. Chinese tourists coming to Cracow are predominantly young people (often students) travelling with their family, friends, or partners. This is usually their first visit to Poland and is often a short stay in transit from/to Prague and Budapest.

2. They are prompted to visit Poland by the information found online (mainly in English, as they can find barely any Internet sources in Chinese) and by their friends' and relatives' opinions.

3. Their main reason to come is tourism in search for tradition, culture, historical sites, landscapes, and low costs. These expectations are well fulfilled, and the tourists' overall satisfaction is very high.

4. Chinese tourists find Poland different from other Western European countries, rather traditional, with a long and rich history; they see it as a developing country which is safe, remarkable, and inexpensive.

5. Their knowledge of Poland as a country and tourist destination is rather limited.

6. The main problem they encounter is the language barrier, that is the lack of information in Chinese - both online and once on site.

In relation to the effectiveness of the marketing efforts undertaken by Poland in the Chinese market (the secondary goal of the study), the research has shown their weak impact and Chinese tourists' ambivalent opinion about the key message of the promotional campaign "Poland. Come and find your story". 
Taken together, these results suggest that if Polish authorities really consider China a strategic tourist source market, there is a need to intensify expenditure not only on promotion (mainly online) but also on the removal of language-based communication problems. There is also scope for expanding the tourist offer dedicated to Chinese tourists - both in Poland and in cooperation with other Central European countries.

The major limitation of this study is the structure of the sample, which is probably biased towards independent young travellers. Hence, the findings may be interpreted as considering mainly this segment of the market. Given the exploratory nature of this study, further research should examine larger samples to include a higher number of other types of travellers (so as to enable a reliable cross-group comparison). It would be also interesting to survey Chinese travellers in places in Poland other than Cracow or Warsaw, in order to understand their motivations and information sources.

\section{Literature}

1. UNWTO. (2015). Tourism highlights, 2015 Edition. Madrid: World Tourism Organization.

2. UNWTO. (2005). Tourism highlights, 2005 Edition. Madrid: World Tourism Organization.

3. UNWTO. (2014). Tourism highlights, 2014 Edition. Madrid: World Tourism Organization.

4. UNWTO. (2013). Tourism highlights, 2013 Edition. Madrid: World Tourism Organization.

5. UNWTO. (2012). Tourism highlights, 2012 Edition. Madrid: World Tourism Organization.

6. UNWTO. (2011). Tourism highlights, 2011 Edition. Madrid: World Tourism Organization.

7. UNWTO. (2010). Tourism highlights, 2010 Edition. Madrid: World Tourism Organization.

8. WTM. (2012). WTM Global trends report. In the global event "World Travel Market", 5-8 November 2012, London.

9. China Outbound Tourism in 2015. TravelChinaGuide.com. Retrieved June 4, 2016, from www.travelchinaguide.com/ tourism/2015statistics/outbound.htm.

10. BMI. (2011). Emerging outbound markets. Business Monitor International, October 2011. Retrieved June 4, 2016, from www.businessmonitor.com/.
11. Nessel K. (2013). Chinese tourists as an opportunity for the European tourism industry. In M. Bednarczyk, E. Wszendybył-Skulska (eds.), Management of tourism in crises. Education and brand (pp. 67-83). Warszawa: CeDeWu. [in Polish]

12. Central Statistical Office. (2015). Tourist accommodation. December 2015. Retrieved June 4, 2016, from http://stat. gov.pl/obszary-tematyczne/kultura-turystyka-sport/turystyka/turysci-w-bazie-noclegowej-grudzien-2015-r-,5,41. html. [in Polish]

13. Amonhaemanon D., Amornhaymanon L. (2015). Mainland Chinese tourist behavior and motivations: Evidence from two destinations in Southern Thailand. Proceedings of $12^{\text {th }}$ Asian Business Research Conference, 8-9 October 2015, Novotel Hotel Bangkok on Siam Square, Bangkok, Thailand.

14. Davies R. (2003). Branding Asian tourist destinations - A Series. Retrieved May 12, 2004, from www.asiamarketresearch.com/columns/tourism-branding.htm.

15. Henkel R., Henkel P., Agrusa W., Agrusa J., Tanner J. (2006). Thailand as a tourist destination: Perceptions of international visitors and Thai residents. Asia Pacific Journal of Tourism Research 11(3), 269-287.

16. Tapachai N., Waryszak R. (2000). An examination of the role of beneficial image in tourist destination selection. Journal of Travel Research 39(1), 37-44.

17. Walas B., Chichooska A., Buczak T., Zientalska D., Malazek M., Celuch K. (2011). Marketing strategy of Poland in tourism for 2012-2020. Warszawa: Polska Organizacja Turystyczna. [in Polish]

18. Borkowski K., Grabiński T., Seweryn R., Wilkońska A., Mazanek L., Grabińska E. (2015). Tourism in Cracow in 2015. Kraków: Małopolska Organizacja Turystyczna. [in Polish]

19. BCG. (2011). Taking off. Travel and tourism in China and beyond. Boston Consulting Group, Boston, March 2011, Retrieved January 4, 2013, from www.bcg.com/documents/ file74525.pdf.

20. Latham K. (2011). How the rise of Chinese tourism will change the face of the European Travel Industry. School of Oriental and African Studies, University of London. Retrieved January 4, 2013, from www.citsmice.net/other-reports/07_ HiltonSOASBluePaperEnglish.pdf.

Submitted: July 11, 2016

Accepted: December 29, 2016 